Palabra Clave (La Plata), octubre 2017, vol. 7, n 1, e029. ISSN 1853-9912

Universidad Nacional de La Plata.

Facultad de Humanidades y Ciencias de la Educación.

Departamento de Bibliotecología

\title{
Preservação do patrimônio documental arquivístico em ambiente digital
}

\author{
Preservation of archival documentary heritage in \\ digital environment
}

\author{
Henrique Machado dos Santos *, Daniel Flores * \\ * Universidade Federal de Santa Maria, Brasil | henrique.hms.br@gmail.com, \\ dfloresbr@gmail.com
}

\section{PALAVRAS-CHAVE}

Documento digital

Preservação digital

Patrimônio documental

Arquivística

Arquivo

\section{KEYWORDS}

Digital record

Digital preservation

Documentary heritage

Archival science

Archive

\section{RESUMO}

Este artigo perpassa a ideia do documento arquivístico digital como parte integrante do patrimônio cultural, e posteriormente, descrevem-se aspectos pertinentes à sua preservação. Para isto são abordadas questões referentes à garantia de acesso a documentos autênticos no longo prazo. A discussão concentra-se na relação entre estratégias de preservação, repositórios digitais, modelo OAIS, linha de custódia ininterrupta, e atividades de auditoria e certificação. Dentre os apontamentos finais, destaca-se a necessidade de sintetizar os conhecimentos discutidos a fim de fornecer subsídios teóricos para facilitar a sua aplicação no âmbito da arquivística.

\section{ABSTRACT}

This article pervades the idea of the digital record as an integral part of the cultural heritage, and later, it describes pertinent aspects to its preservation. For this, issues related to guaranteeing access to authentic records in the long term are addressed. The discussion focuses on the relationship between preservation strategies, digital repositories, OAIS model, uninterrupted custody line, and audit and certification activities. Among the final notes, it is necessary to synthesize the knowledge discussed in order to provide theoretical subsidies to facilitate its application in the archival science.

Recibido: 17 de mayo de 2017 | Aceptado: 5 de septiembre de 2017 | Publicado: 9 de octubre de 2017 


\section{Introdução}

Os constantes avanços das tecnologias da informação e comunicação impulsionaram a renovação dos meios de troca de informações, tendo a praticidade como sua principal aliada no processo de aceitação pelo público geral. Esta demanda informacional teve como consequência, o aumento da informação registrada, principalmente, em meio digital. Resumidamente, pode-se dizer que tais fatos contribuíram para o surgimento dos documentos digitais.

As funções administrativas se modernizaram, tendo o computador e as ferramentas de tecnologia da informação e comunicação como aliados na busca por eficiência e eficácia. Logo surgem documentos administrativos em meio digital, os quais posteriormente ao cumprimento de seus valores primários serão avaliados no âmbito da arquivística, e caso possuam valor secundário, serão preservados em caráter permanente, integrando o patrimônio documental.

Entretanto, a demanda por documentos digitais tem sido inversamente proporcional aos avanços na pesquisa em preservação digital, de modo que documentos estão sendo produzidos sem garantias de que haverá conhecimentos suficientes e tecnologias capazes de preservá-los. Desta forma, o presente estudo trás consigo uma abordagem reflexiva perpassando a contextualização do documento arquivístico no escopo do patrimônio, a presunção de autenticidade, a necessidade de gerar confiança ao ambiente digital, as estratégias de preservação, e os repositórios digitais. Por fim, há uma síntese que discorre sobre a relação destes tópicos com o modelo de referência Open Archival Information System (OAIS), a linha de custódia ininterrupta e o processo de auditoria e certificação de repositórios digitais.

A metodologia utilizada consiste em um levantamento bibliográfico de materiais previamente publicados, dentre estes, livros, teses, dissertações e artigos científicos recuperados pela ferramenta de pesquisa Google Scholar a qual possui acesso a conteúdos indexados em diversas bases de dados. Desta forma, este estudo configura-se como um artigo de revisão de literatura tendo o caráter assistemático, que parte de obras de referência para estabelecer um diálogo entre a arquivística, a preservação digital e o patrimônio cultural (Gil, 2010; Silva y Menezes, 2005; Luna, 1997).

\section{Patrimônio: breve contextualização}

O conceito de patrimônio é muito amplo e vai além de questões relacionadas à acumulação de riqueza proporcionada pelo sistema capitalista. Em uma perspectiva social e humana, o patrimônio pode ser dividido em três categorias: cultural, histórico e natural.

O patrimônio histórico consiste no conjunto de bens que representam a história de uma sociedade, para isto, ele utiliza de aspectos da arquitetura da época, obras de arte, documentos em geral e objetos que mantenham uma forte relação com o contexto histórico.

A expressão [patrimônio histórico] designa um bem destinado ao usufruto de uma comunidade que se ampliou a dimensões planetárias, constituído pela acumulação contínua de uma diversidade de objetos que se congregam por seu passado 
comum: obras e obras-primas das belas-artes e das artes aplicadas, trabalhos e produtos de todos os saberes e savoir-faire dos seres humanos (Choay, 2006, p. 11).

A construção dos sujeitos segue a linha de pensamento de Choay (2006), visto que o patrimônio histórico auxilia na compreensão da identidade tendo importante influência na manutenção dos usos e dos costumes populares de uma determinada sociedade.

Já o patrimônio cultural é representado pelo conjunto de bens materiais e imateriais, que representam a memória, a identidade e a história dos costumes de uma determinada sociedade. Desta forma, é possível conscientizar os indivíduos, através da aquisição de conhecimentos que auxiliem na compreensão de sua história local.

Memória e identidade se concentram em lugares os quais desafiam o passar do tempo e assim são reconhecidos (Candau, 2014). Logo, a possibilidade de registrar e arquivar memórias proporciona a imortalidade das pessoas (Abreu, 1996). Desta forma, a preservação de registros documentais que contextualizem as diferentes representações do patrimônio irá corroborar para a sua compreensão e consequentemente, para a preservação de sua lembrança às gerações futuras.

O patrimônio natural, por sua vez, consiste na relação entre o homem e o meio ambiente, mais precisamente no que se refere à fauna e a flora. Observa-se que este ambiente possui uma relação com os indivíduos que nele vivem, havendo assim uma interação que influencia o cotidiano das sociedades.

O patrimônio ainda poderá ser classificado como material ou imaterial. O patrimônio material está relacionado aos objetos concretos, mais precisamente, àqueles que atuam como fontes de informações aos indivíduos. Já o patrimônio imaterial é composto pelo conjunto de manifestações sociais as quais são transmitidas, recriadas e modificadas de forma assistemática ao longo do tempo.

\section{1. Desdobramentos patrimoniais}

O patrimônio pode configurar diferentes expressões culturais, representado, na forma de prédios, documentos, monumentos, entre outros. É pertinente destacar que há um aumento do "conjunto de patrimônio", ou seja, nunca "se arquivou" tanto, "se colecionou" tanto como na contemporaneidade. Tal fato pode ser apontado como uma consequência de se vivenciar a "era da informação", fase na qual a sociedade tem grandes demandas por conteúdos, e da mesma forma surge a consciência e o dever de disponibilizar e difundir estes conteúdos.

O patrimônio não existe apenas para representar ideias e valores abstratos, e assim ser compreendido, ele vai além, constrói e forma as pessoas (Gonçalves, 2009). Desta forma, o patrimônio molda os indivíduos conforme as características culturais do meio em que vivem, tendo influência em sua cultura, seus costumes, linguagens, crenças e vestimentas.

... a elaboração do patrimônio segue o movimento das memórias e acompanha a construção das identidades: seu campo se expande quando as memórias se tornam 
mais numerosas; seus contornos se definem ao mesmo tempo em que as identidades colocam, sempre de maneira provisória, seus referenciais e suas fronteiras; pode assim retroceder quando ligada a identidades fugazes ou que os indivíduos buscam dela se afastar. O patrimônio é menos um conteúdo que uma prática de memória obedecendo a um projeto de afirmação de si mesma. Esse projeto está destinado a permanecer sempre inacabado; ele pode mesmo se esgotar na esperança de chegar a uma memória total (Candau, 2014, pp. 163164).

O conceito de inacabado explicitado por Candau (2014) reforça que o patrimônio nunca estará completo, logo, sempre haverá um novo item ou aspecto a ser incorporado, e consequentemente, tem-se um constante crescimento patrimonial. Observa-se que, na medida em que o patrimônio se expande, o desafio de preservar se torna maior visto que haverá maior amplitude temporal e diversidade de objetos a serem concebidos como integrantes do patrimônio.

\section{2. Os lugares de memória e a identidade cultural: a perspectiva do arquivo}

$\mathrm{Na}$ medida em que as sociedades passadas evoluíram em sua organização houve, paralelamente, o desenvolvimento de uma consciência em relação ao valor dos documentos como meio de registro de suas diversas atividades. Tal fato resultou no surgimento dos arquivos com o objetivo de guardar os tesouros culturais da época (Paes, 2004).

Posteriormente, foi possível identificar a presença do patrimônio cultural nos documentos que, em virtude de seu valor mediato, possuem interesse probatório, informativo, social e/ou histórico. Estes documentos já cumpriram o seu valor imediato na administração e passam a ser dotados de um valor secundário; por esta razão são preservados em caráter permanente. Os documentos arquivísticos "saem da administração" para "entrar na história", após perpassarem pela avaliação e serem considerados de valor permanente.

... o documento de valor permanente é um bem cultural móvel, componente do patrimônio cultural nacional. Como tal, ele tem direitos assegurados à sua integridade física e, tal como outras modalidades de bens culturais, recebe o amparo legal quanto ao seu domicílio, guarda e proteção dentro do meio administrativo, jurídico e social que Ihe deu origem, função e sentido (Bellotto, 2014, p. 92).

Tais "direitos assegurados" estão implícitos na Lei no 8.159, de 8 de janeiro de 1991. Em suas disposições gerais, mais precisamente no artigo primeiro, define que: cabe ao Poder Público realizar a gestão documental e a preservação dos documentos de arquivo, como instrumentos de apoio à administração, à cultura, ao desenvolvimento científico e fontes de prova e informação (Brasil, 1991). Esta lei é um importante instrumento jurídico para proteção dos arquivos brasileiros, de modo que seus documentos não possam ser eliminados de forma arbitrária e indiscriminada. Deste modo, adiciona responsabilidade e prestígio ao trabalho dos profissionais do arquivo; assim, os documentos arquivísticos representam questões de interesse social, além de possuir um resguardo legal. 
Observa-se que a justificativa do tratamento dos arquivos para fins culturais, patrimoniais e/ou de investigação tem base na sua qualidade de testemunhos (Rousseau e Couture, 1998). Sendo válido ressaltar o caráter imparcial dos documentos de arquivo, visto que são gerados para satisfazer atos administrativos de uma determinada organização.

Um último aspecto a ser destacado no âmbito dos acervos é a questão da evolução dos documentos arquivísticos. O avanço das tecnologias da informação e comunicação, e a demanda social por estas ferramentas, impulsionaram a produção da informação em meio digital, desta forma ocorreu o advento do documento arquivístico digital. Pode-se apontar que a presença da informação digital nos arquivos desencadeou um processo de reformulação de conceitos na área, vindo a modificar o campo de atuação do arquivista.

Ressalta-se que os documentos digitais não são uma exclusividade da arquivologia, pois já há informação digital sendo preservada, por exemplo, nos museus e nas bibliotecas. Mesmo assim, faz-se uma ressalva, visto que cada ambiente (arquivo, biblioteca e museu) possui uma sistemática de gestão, preservação e acesso aos materiais custodiados. Ainda assim, os referenciais teóricos e as soluções para armazenar estes materiais poderão ser compartilhados de modo que cada área os adapte ao seu contexto teórico-prático.

$\mathrm{Na}$ medida em que as sociedades vão evoluindo, novas tecnologias vão surgindo e deixando seu legado histórico. Desta forma, há diferentes marcos históricos com significados muito particulares e pertinentes ao seu contexto.

\section{Documento arquivístico digital}

O documento digital pode ser definido como aquele acessado e interpretado por meio de um sistema computacional (Brasil, 2011; 2012), armazenado em suporte magnético, óptico ou óptico-magnético, formado por uma sequência de bits que é lida indiretamente pelas plataformas de hardware e software (Innarelli, 2012). E para ser considerado um documento arquivístico digital, deverá ainda ser produzido ou recebido através de uma atividade (Brasil, 2011; 2012).

Atualmente, uma parcela significativa de documentos arquivísticos está sendo produzida exclusivamente em formato digital (Innarelli, 2011; InterPARES, 2007b; Thomaz, 2005; 2006; Brasil, 2004a,b), de modo que estes registros ganham relevância como fonte de informação (Innarelli, 2009). Tal fato é impulsionado pelas vantagens que o meio digital proporciona como, por exemplo, a facilidade de acesso e a economia de espaço físico. Contudo, a ausência de procedimentos adequados de segurança e de preservação acarretam incertezas quanto a sua confiabilidade, autenticidade e acesso futuro. Tais entraves podem desqualificar o seu valor como prova das atividades desenvolvidas (Rocha y Silva, 2007).

Em resumo, os documentos arquivísticos em meio digital necessitam de um tratamento diferenciado se comparados aos documentos analógicos. Tal aspecto reforça a necessidade de intervenção humana, por meio das atividades de preservação digital.

\section{1. Autenticidade}

A autenticidade possui duas características que são: integridade e identidade. Desta 
forma, um documento para ser considerado autêntico depende do sistema informatizado no qual está inserido.

A integridade consiste na qualidade daqueles documentos que se encontram completos e que não sofreram nenhum tipo de corrupção ou alteração não autorizada nem documentada (Brasil, 2011). O conteúdo e os dados são considerados inalterados quando forem idênticos ao valor e à apresentação do conteúdo e dos dados da primeira manifestação salva do material (InterPARES, 2007b), transmitindo exatamente a mesma mensagem que levou à sua produção para atingir seus objetivos (Brasil, 2012). A integridade da informação está associada e dependente dos recursos de segurança relacionados à tecnologia da informação utilizados no processamento, armazenamento e transmissão (De Sordi, 2008).

Já a identidade corresponde ao conjunto dos atributos de um documento arquivístico que o caracterizam como único, capaz de identificar e distinguir um determinado documento arquivístico dos outros. Dentre estes atributos podem ser considerados, por exemplo: data, autor, destinatário, assunto, número identificador, número de protocolo (Brasil, 2012; InterPARES, 2007b).

A preocupação com a preservação da autenticidade dos documentos digitais deve-se a necessidade de garantir que o patrimônio documental custodiado é autêntico e permanecerá íntegro no decorrer do tempo (Corrêa, 2010). Esta preocupação é manifestada pelo Conselho Nacional de Arquivos (Brasil, 2012), órgão vinculado ao Arquivo Nacional do Brasil, conforme o seu documento Diretrizes para a presunção de autenticidade de documentos arquivísticos digitais, segundo o qual:

Os documentos arquivísticos digitais apresentam dificuldades adicionais para presunção de autenticidade em razão de serem facilmente duplicados, distribuídos, renomeados, reformatados ou convertidos, além de poderem ser alterados e falsificados com facilidade, sem deixar rastros aparentes (Brasil, 2012, p. 1).

A questão da autenticidade esta diretamente relacionada ao processo de criação, manutenção e custódia dos documentos arquivísticos (Rondinelli, 2005), e é ameaçada sempre que os documentos arquivísticos são transmitidos através do espaço ou do tempo e por efeitos da obsolescência tecnológica (Brasil, 2012).

Os documentos arquivísticos digitais necessitam de um tratamento diferenciado, pois possuem características próprias em relação a sua comprovação de autenticidade (Sousa, 2009). Além disto, são vulneráveis à fragilidade implícita de seus objetos digitais, são de fácil adulteração e estão sujeitos aos ciclos de obsolescência tecnológica cada vez mais acelerados (Brasil, 2014; 2015). Este conjunto de complexidades implícitas ao registro binário, aliado às especificidades tecnológicas para acessar os documentos, demonstram que a preservação e garantia de acesso a documentos arquivístico digitais autênticos é o desafio à arquivologia do século XXI.

Os documentos arquivísticos digitais devem ter a sua autenticidade preservada ao longo do tempo, desde a sua produção até o momento de sua transferência ou recolhimento aos arquivos permanentes (Innarelli, 2009). No meio digital, os problemas relacionados com a autenticidade são semelhantes aos do meio analógico. Porém, a simplicidade com que se 
podem realizar alterações, a rapidez com que estas podem ser disseminadas e a dificuldade em detectá-las tornam o problema mais complexo (Ferreira, 2006).

Para preservar documentos digitais autênticos, será necessário manter o registro do conjunto de processos que garantem o seu acesso contínuo, confiabilidade e integridade (Márdero Arellano, 2008). Ou seja, os procedimentos aos quais os documentos foram submetidos durante a sua custódia deverão ser registrados através de metadados. Além disso, o público e os especialistas deverão conhecer os procedimentos utilizados pelo preservador, para deixar clara a maturidade dos serviços de preservação digital e, consequentemente, gerar confiança.

\section{2. Confiabilidade}

Dentre os desafios apresentados pelos documentos digitais é possível citar a produção de documentos confiáveis, a manutenção de sua autenticidade e o acesso contínuo em longo prazo (Rocha y Silva, 2007). A ausência de confiabilidade acaba por ofuscar os investimentos e os esforços realizados para manutenção da autenticidade. Logo, é preciso que as instituições que custodiam materiais digitais definam boas práticas de preservação digital.

Para agregar confiabilidade será preciso manter uma cadeia de custódia ininterrupta, na qual os documentos devem estar inseridos desde a sua produção até a sua transferência e/ou recolhimento para o responsável por sua preservação em longo prazo (Brasil, 2012). Caso esta cadeia de custódia seja interrompida, isto será o suficiente para gerar dúvidas em relação à autenticidade do documento (Brasil, 2012; InterPARES, 2007a) em virtude de sua vulnerabilidade no que tange a manipulação/falsificação de informações. Conforme o Conselho Nacional de Arquivos (Brasil, 2011):

A confiabilidade está relacionada ao momento em que o documento é produzido e à veracidade do seu conteúdo. Para tanto, há que ser dotado de completeza e ter seus procedimentos de produção bem controlados. Dificilmente pode-se assegurar a veracidade do conteúdo de um documento; ela é inferida da completeza e dos procedimentos de produção. A confiabilidade é uma questão de grau, ou seja, um documento pode ser mais ou menos confiável (Brasil, 2011, p. 21).

A confiabilidade não pode ser entendida como um status de "confiável" e "não confiável", e sim como uma variável que depende do contexto tecnológico onde está situado o acervo. Conforme De Sordi (2008), a informação confiável é aquela a qual os usuários conferem credibilidade, embora seja uma informação que não possua veracidade absolutamente comprovada, a informação confiável é uma informação em que se acredita.

No caso da informação registrada/documentada, a confiabilidade dependerá da conformidade dos documentos digitais com os princípios da arquivologia (proveniência, unicidade, identidade e integridade) e da diplomática (forma fixa, conteúdo estável e variabilidade limitada). A criação de um ambiente confiável para a preservação de documentos digitais implica em estabelecer métodos de preservação que satisfaçam exigências do público pesquisador.

Neste sentido, é preciso implementar softwares e políticas de gestão e preservação de 
documentos digitais, que visem o aumento da confiabilidade do sistema. Com o tempo, estas iniciativas atingirão os níveis de confiança desejados pelo público-alvo.

\section{Preservação digital}

A preservação de documentos arquivísticos digitais consiste em garantir a autenticidade das informações registradas no suporte, a fim de possibilitar o acesso contínuo aos seus conteúdos e funcionalidades no longo prazo (Brasil, 2004b). Para isto, a informação contida no documento deverá ser interpretada no futuro, por uma plataforma tecnológica diferente da qual foi utilizada no momento de sua criação (Brasil, 2004a; Ferreira, 2006). Observa-se aqui um pertinente entrave, visto que não há como saber antecipadamente quais serão as tecnologias utilizadas no futuro, tampouco como será o seu funcionamento.

Para que os documentos digitais possam atingir a longevidade, o estudo da preservação digital deverá ser abordado de forma interdisciplinar (Innarelli, 2011), contemplando políticas de preservação, as quais irão descrever claramente, como, por exemplo, as estratégias de preservação digital a serem aplicadas. (Ferreira, 2006).

A complexidade e a fragilidade dos documentos digitais levam ao entendimento de que a preservação digital não é e nunca será resolvida pela própria tecnologia (Innarelli, 2011). Logo, a implementação de políticas de preservação será considerada a iniciativa mais eficaz para preservar e garantir o acesso em longo prazo (Márdero Arellano, 2004). Esta política deverá identificar os riscos a fim de evitá-los ou minimizá-los, e contemplar a gestão de segurança seguindo padrões amplamente aceitos. Além disso, será preciso estabelecer um plano de ação para garantir efetivamente as condições de acesso necessárias no longo prazo (Casanovas, 2008).

Em síntese, a preservação digital consiste em garantir o acesso contínuo em longo prazo, objetivando a manutenção da autenticidade dos documentos digitais. Estes documentos deverão ser corretamente interpretados por plataformas de hardware e software diferentes das quais foram originados. Sendo assim, entende-se a preservação digital como uma atividade que transcende o tempo, a plataforma tecnológica e o suporte de armazenamento.

\section{1. Estratégias de preservação digital}

A preservação digital é composta por procedimentos de ordem estrutural e operacional (Márdero Arellano, 2004; Thomaz, 2004). Os procedimentos estruturais são os investimentos iniciais como, por exemplo, normas, padrões e infraestrutura.

Já os de ordem operacional são as atividades aplicadas para a preservação física, lógica e intelectual dos documentos digitais, como, por exemplo, migração, emulação, encapsulamento e refrescamento.

Pode-se entender que os procedimentos estruturais compreendem as políticas de preservação, e os operacionais se referem às estratégias de aplicação técnica, as quais consistem em intervenções diretas em nível de hardware, software, suporte e na própria sequência de bits do documento. 
Uma estratégia de preservação digital compreende um conjunto de objetivos e métodos para efetuar a manutenção em longo prazo dos documentos digitais, contemplando seus respectivos componentes digitais, e garantindo a sua autenticidade (Webb, 2003). Entretanto, nenhuma estratégia se mostrou eficaz a ponto de ser aplicada genericamente (Brasil, 2004b; Ferreira, 2006), o que torna necessário o desenvolvimento de diversas investigações. Desta forma, a implementação de tais estratégias visa minimizar os problemas causados pela obsolescência tecnológica, como por exemplo, dificuldades de leitura, incompatibilidade de versões, e até mesmo, a perda de informações relacionadas aos documentos.

\section{2. Repositório arquivístico digital confiável}

Um dos primeiros procedimentos para a preservação de documentos digitais deverá ser a transferência destes para um repositório digital (Márdero Arellano, 2008). Para este, será designado o compromisso com a preservação, o gerenciamento e o acesso contínuo em longo prazo de documentos arquivísticos digitais autênticos (Brasil, 2014; 2015).

Tradicionalmente, os arquivos, as bibliotecas e os museus são encarregados pela guarda do patrimônio cultural por serem instituições que adquiriram, ao longo do tempo, a confiança necessária para armazenar materiais de tal valor. Estas instituições são tidas como confiáveis para preservar tais registros nas melhores condições, bem como fornecer o acesso para as futuras gerações (Thomaz, 2007). Logo, pode-se dizer que a confiança é adquirida com o passar do tempo, mediante demonstração de competência para tal. No caso dos documentos digitais, será necessário comprovar a eficácia do repositório digital em questão, tornando-se então, um repositório arquivístico digital confiável (RDC-Arq).

É fundamental que o repositório digital facilite a implementação das políticas de preservação e das estratégias que serão utilizadas (Ferreira, 2006). Desta forma, um RDC-Arq deverá ser capaz de atender aos procedimentos arquivísticos e aos requisitos de confiabilidade (Brasil, 2014; 2015). Tal confiança se desenvolve em diversos níveis, havendo um mínimo necessário que são três níveis: produtores, consumidores e fornecedores. Logo, é preciso verificar se os produtores estão enviando as informações corretas, se os consumidores estão recebendo as informações corretas, e se os fornecedores estão prestando serviços adequados (Thomaz, 2007).

A confiabilidade deve ser considerada nas medidas de segurança, desde a construção do RDC-Arq para garantir que os materiais armazenados permanecerão autênticos no logo prazo (Márdero Arellano, 2008). Deste modo, será preciso seguir padrões e procedimentos amplamente aceitos pela comunidade (de preservação e de usuários), demonstrando assim, que os documentos arquivísticos digitais permanecem autênticos no longo prazo.

Neste contexto, os processos de auditoria e certificação são essenciais para verificar a confiabilidade dos métodos de preservação empenhados pelos repositórios digitais. A auditoria é realizada em um primeiro momento, verificando assim a conformidade do repositório digital com o modelo OAIS e com requisitos de ordem tecnológica e organizacional pré-estabelecidos.

Inicialmente a auditoria segue um determinado modelo que é usado para determinar um 
conjunto de dados capaz de quantificar as potencialidades e as vulnerabilidades do repositório; após a interpretação destes dados, o repositório digital será certificado como repositório digital confiável.

As atividades de certificação estão diretamente relacionadas com as de auditoria, sendo executadas a posteriori como um complemento capaz de mensurar o nível do confiança dos repositórios digitais. Desta forma, a certificação precisa ser realizada por uma organização competente para tal e devidamente registrada nos termos legais deste serviço, visto que os requisitos para exercer tal atividade variam de acordo com a legislação de cada país. Conforme Thomaz (2007), a constante certificação demonstrará confiança nos métodos empregados pelo repositório, sendo válido destacar a pertinência de implementar padrões amplamente aceitos pela comunidade de preservação, como por exemplo, o modelo OAIS.

\subsection{0 modelo de referência Open Archival Information System}

A implementação de repositórios arquivísticos digitais deverá seguir normas definidas previamente. Neste caso, o Conarq comenta que a norma mais importante da área é o OAIS (Brasil, 2014; 2015). Esta norma oferece uma referência sólida para os termos, conceitos e fluxos de informações que circunscrevem um repositório OAIS, porém não prescreve sua implementação (Sayão, 2010).

A Figura 1 - Os três atores do ambiente OAIS -, apresenta uma visão resumida contendo: produtor, administrados e consumidor, os quais possuem relação direta como o arquivo (OAIS).

Figura 1. Os três atores do ambiente OAIS

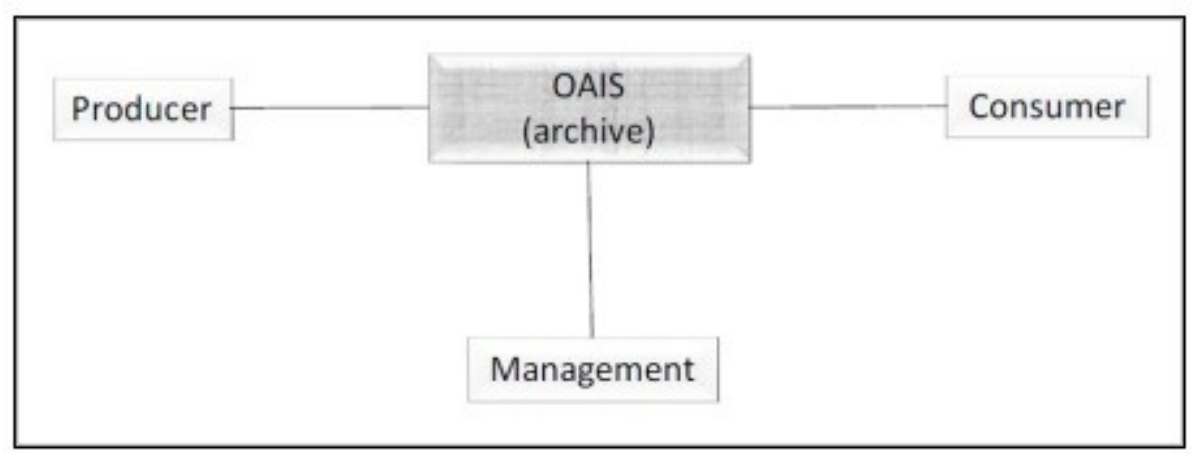

Fonte: Consultative Committee for Space Data System (2012, p. 28).

Inicialmente, o produtor (producer) é o responsável pelos documentos de valor primário, os quais serão submetidos à avaliação e posteriormente recolhidos ao arquivo permanente (OAIS) para preservação em longo prazo. Cabe ao administrador do OAIS (management) a definição de políticas de preservação digital, as quais englobam questões como os padrões de formatos e as estratégias de preservação a serem implementadas. Por fim, o material de caráter ostensivo submetido pelo produtor, e preservado no ambiente OAIS pelo administrador, poderá ser acessado pelo consumidor (consumer). Ressalta-se que é preciso proporcionar condições de acesso ao consumidor, bem como demonstrar que os 
materiais custodiados são preservados através de métodos confiáveis.

A literatura técnica sobre preservação digital aponta que a conformidade dos repositórios digitais com o modelo OAIS adicionará confiança nas ações de preservação. O fato de o OAIS ser apenas um modelo conceitual possibilita a sua implementação utilizando uma variabilidade de repositórios, bem como é possível escolher um padrão entre diversos padrões de metadados. Além disso, é possível escolher os softwares responsáveis pelas estratégias de preservação, como por exemplo, migrações, conversões e emulações. Desta forma, o acesso em longo prazo dependerá da eficácia destas ferramentas que executam as estratégias, por isto é de extrema importância que exista uma avaliação criteriosa e uma verificação constante destas ferramentas.

Para garantir o acesso contínuo à informação no longo prazo torna-se indispensável à criação de repositórios digitais, tendo o auxílio de softwares que lhes permitam um melhor controle dos processos relacionados à manutenção dos documentos digitais. No entanto, é necessário ter em mente o modelo de referência OAIS durante a implementação do repositório (Lopes, 2008). Além disso, deve existir em simultâneo um modelo de informação onde se encontram descritos os requisitos de metadados para a preservação em longo prazo (Saramago, 2004).

A implementação de um arquivo em concordância com os modelos de funcionalidade e estrutura da informação do OAIS é considerada o pré-requisito para se estabelecer os repositórios confiáveis, garantindo a preservação em longo prazo (Márdero Arellano, 2008). Deste modo, estima-se que com modelo OAIS, as instituições arquivísticas passarão a entender com maior clareza os requisitos necessários para a preservação (Thomaz, 2006).

A definição de um repositório digital confiável deverá considerar os termos do OAIS, manter uma linha de custódia ininterrupta, além de ser submetido a processos de auditoria e certificação. A sincronia entre estas definições proporcionará um ambiente confiável para a preservação em longo prazo. Logo, tomam-se estes conceitos com base para a recomendação de qualquer repositório digital para preservar documentos autênticos.

\section{Síntese e perspectivas}

A caracterização do documento digital como arquivístico implica em inseri-lo no âmbito do patrimônio documental, visto que tende a registrar as memórias individuais e coletivas, da mesma forma que ocorre com o documento analógico. No entanto, a obsolescência dos componentes de hardware, software e do próprio suporte, impõe desafios quanto à preservação de longo prazo; e torna necessária a interferência humana no processo.

A preservação digital surgiu como um meio para realizar a manutenção dos documentos e garantir o acesso em longo prazo, mantendo sua autenticidade. Desta forma, as estratégias tem um papel fundamental, as estruturais definem questões relacionadas à infraestrutura técnica, tecnológica e as políticas; já as operacionais são intervenções diretas em nível de hardware, software e suportes. Neste ponto, há necessidade de se implementar um repositório digital, de modo que gerencie a execução das estratégias, 
controle o acesso aos conteúdos e realize a difusão do patrimônio documental.

A literatura técnica de preservação digital aponta o modelo OAIS como padrão de referência na preservação de longo prazo. Observa-se que seus requisitos se adequam às perspectivas da arquivística, em especial no que tange a preservação e garantia de acesso contínuo a documentos autênticos no longo prazo. Desta forma, o modelo OAIS é tido como o padrão a ser seguido na implementação de repositórios arquivísticos digitais confiáveis, contemplando uma linha de custódia ininterrupta, a qual se estende desde a produção dos documentos arquivísticos digitais, perpassando a gestão, e atingindo a preservação e o acesso.

Através de uma linha de custódia ininterrupta é possível manter evidências de que o patrimônio documental foi custodiado de forma segura, utilizando procedimentos como o monitoramento contínuo. Tais evidências consistem em registrar através dos metadados todas as alterações realizadas sobre os documentos custodiados. Assim, obtém-se um histórico que contém, por exemplo, todos os emuladores utilizados, quais as migrações realizadas, e as possíveis alterações da custódia documental. Desta forma, a convergência entre repositório digital, OAIS e linha de custódia ininterrupta fornece subsídios teóricos para garantir que o patrimônio documental custodiado seja autêntico.

Por fim, salienta-se que as atividades de auditoria e certificação de repositórios digitais atuam na mensuração da confiança do repositório. O processo de auditoria verificará a conformidade do repositório com o modelo OAIS, bem como questões relacionadas à segurança, missão e infraestrutura do repositório e, posteriormente, a certificação definirá se o repositório atingiu os requisitos mínimos para ser considerado confiável.

\section{Considerações finais}

Este artigo realizou uma reflexão na qual o documento arquivístico digital é entendido no contexto do patrimônio documental, e assim, requere métodos específicos para a sua preservação em longo prazo. O advento do documento digital na arquivística surge em virtude da praticidade e consequente disseminação de tecnologias da informação e comunicação, as quais evoluem em ritmo acelerado, gerando ciclos cada vez mais curtos de obsolescência tecnológica.

Inicialmente discorreu-se sobre conceitos fundamentais do patrimônio, e tem-se em vista a sua pertinência na formação da identidade e da memória social. Destaca-se que o século XXI apresenta novos desafios quanto à preservação do patrimônio, seja ele, cultural, histórico ou natural. Há tendências significativas quanto à preservação, e isto implica em uma expansão das formas e dos bens patrimoniais.

Esta mesma tendência se aplica no nível dos documentos arquivísticos, sejam digitais ou analógicos. Os documentos digitais demandaram a necessidade de reformular o conceito de documento arquivístico, ampliando a diversidade de suportes. Da mesma forma que alterações no conceito, o documento digital trouxe a necessidade de tratamento diferenciado, logo, sua manutenção é considerada em nível de hardware, software e suporte.

Conforme observado, as estratégias estão em um nível inicial, embora necessárias, é 
altamente recomendável implementar um repositório digital em conformidade com o modelo OAIS para auxiliar a execução das estratégias. Além disso, é preciso manter uma linha de custódia ininterrupta que se estende desde a produção do documento até a preservação e o acesso. Tal sistemática é capaz de preservar documentos arquivísticos digitais autênticos e garantir o seu acesso contínuo no longo prazo. E em caráter complementar, as atividades de auditoria e certificação definem os níveis de confiança do repositório, classificando-o como RDC-Arq.

Por fim, o campo da preservação digital demonstra que há diversos segmentos a serem explorados, no entanto, há necessidade de maior aproximação entre estes para fornecer subsídios teóricos às praticas. Estratégias de preservação, repositórios digitais, modelo OAIS, linha de custódia ininterrupta e padrões para auditoria e certificação, constituem um conjunto significativo de conhecimentos, os quais, se compilados, podem gerar o núcleo da preservação de documentos arquivísticos digitais. A perspectiva de arquivística consiste na tendência de seguir produzindo documentos digitais e analógicos, constituindo acervos mistos, ambos relevantes ao patrimônio documental. Desta forma, o desafio da preservação e da garantia de acesso contínuo é seu horizonte.

\section{Referências bibliográficas}

Abreu, R. (1996). A fabricação do imortal: memória, história e estratégias de consagração no Brasil. Rio de Janeiro: Rocco.

Bellotto, H. L. (2014). Constituição, dispersão e reintegração de fundos. Em H. L. Bellotto (Ed.), Arquivo: estudos e reflexões (pp. 80-93). Belo Horizonte: UFMG.

Brasil (1991). Lei No 8.159, de 9 de janeiro de 1991. Dispõe sobre a política nacional de arquivos públicos e privados e dá outras providências. Diário Oficial da União. Brasília. Recuperado de http://www.planalto.gov.br/ccivil 03/leis/L8159.htm

Brasil. Conselho Nacional de Arquivos. Câmara Técnica de documentos eletrônicos. (2004a) Carta para a preservação do patrimônio arquivístico digital. Rio de Janeiro: Arquivo Nacional. Recuperado de

http://www.conarq.arquivonacional.gov.br/images/publicacoes textos/Carta preservacao. pdf

Brasil. Conselho Nacional de Arquivos. Câmara Técnica de documentos eletrônicos. (2004b). Gestão arquivística de documentos eletrônicos. Rio de Janeiro: Arquivo Nacional. Recuperado de http://pt.scribd.com/doc/37174068/Gestao-Arquivistica-de-DocumentosEletronicos-CONARQ-Por-Claudia-Rocha

Brasil. Conselho Nacional de Arquivos. Câmara Técnica de documentos eletrônicos. (2011). e-ARQ Brasil: Modelo de Requisitos para Sistemas Informatizados de Gestão Arquivística de Documentos. Rio de Janeiro: Arquivo Nacional. 
Brasil. Conselho Nacional de Arquivos. Câmara Técnica de documentos eletrônicos. (2012). Diretrizes para a presunção de autenticidade de documentos arquivísticos digitais. Rio de Janeiro: Arquivo Nacional. Recuperado de http://www.conarq.arquivonacional.gov.br/images/publicacoes textos/conarq presuncao autenticidade completa.pdf

Brasil. Conselho Nacional de Arquivos. Câmara Técnica de documentos eletrônicos. (2014). Diretrizes para a implementação de repositórios digitais confiáveis de documentos arquivísticos. Rio de Janeiro: Arquivo Nacional. Recuperado de http://proad.ufabc.edu.br/images/Arquivo e Protocolo/diretrizes para a implantacao de repositorios digitais confiaveis de documentos arquivisticos.pdf

Brasil. Conselho Nacional de Arquivos. Câmara Técnica de documentos eletrônicos. (2015). Diretrizes para a implementação de repositórios arquivísticos digitais confiáveis RDC-Arq. Rio de Janeiro: Arquivo Nacional. Recuperado de http://www.conarq.gov.br/images/publicacoes textos/diretrizes rdc arq.pdf

Candau, J. (2014). O jogo social da memória e da identidade (2). Em J. Candau (Ed.), Memória e identidade (pp. 137-180). São Paulo: Contexto.

Casanovas, I. (2008). Gestión de documentos electrónicos. Buenos Aires: Alfagrama.

Consultative Committee for Space Data System (2012). Reference model for an open archival information system (OAIS). Washington: Magenta Book. Recuperado de http://public.ccsds.org/publications/archive/650x0m2.pdf

Corrêa, A. M. G. (2010). Preservação digital: autenticidade e integridade de documentos em bibliotecas digitais de teses e dissertações. Dissertação de Mestrado. Universidade de São Paulo, São Paulo. Recuperado de http://www.teses.usp.br/teses/disponiveis/27/27151/tde-05112010-105831/pt-br.php

Choay, F. (2006). A alegoria do patrimônio. São Paulo: UNESP.

De Sordi, J. O. (2008). Administração da informação: fundamentos e práticas para uma nova gestão do conhecimento. São Paulo: Saraiva.

Ferreira, M. (2006). Introdução à preservação digital: conceitos, estratégias e atuais consensos. Minho: Escola de Engenharia da Universidade do Minho. Recuperado de https://repositorium.sdum.uminho.pt/bitstream/1822/5820/1/livro.pdf

Gil, A. C. (2010). Como elaborar projetos de pesquisa. São Paulo: Atlas.

Gonçalves, J. R. S. (2009). O patrimônio como categoria de pensamento. Em R. Abreu y M. Chagas (Eds), Memória e patrimônio: ensaios contemporâneos (pp. 25-33). Rio de Janeiro: Lamparina.

Innarelli, H. C. (2009). Preservação digital e seus dez mandamentos. Em V. B. Santos (Ed.), Arquivística: temas contemporâneos (pp. 21-75). Distrito Federal: SENAC. 
Innarelli, H. C. (2011). Preservação digital: a influência da gestão dos documentos digitais na preservação da informação e da cultura. Revista digital de biblioteconomia e ciência da informação, 8(2), 72-87. Recuperado de https://periodicos.sbu.unicamp.br/ojs/index.php/rdbci/article/view/1934

Innarelli, H. C. (2012). Instrumenta 2: preservação de documentos digitais. São Paulo: Associação dos Arquivistas de São Paulo.

InterPARES 2 Project (2007a). Diretrizes do Preservador. A preservação de documentos arquivísticos digitais: diretrizes para organizações. TEAM Brasil. Tradução: Arquivo Nacional e Câmara dos Deputados. 2002-2007. Recuperado de http://www.interpares.org/display file.cfm?doc=ip2 preserver guidelines booklet-portuguese.pdf

InterPARES 2 Project (2007b). Diretrizes do Produtor. A elaboração e a manutenção de materiais digitais: diretrizes para indivíduos. TEAM Brasil. Tradução: Arquivo Nacional e Câmara dos Deputados. 2002-2007. Recuperado de http://www.interpares.org/ip2/display file.cfm?doc=ip2 creator guidelines booklet-portuguese.pdf

Lopes, V. (2008). Preservação digital. Minho: Universidade do Minho. Recuperado de http://www.vitorlopes.com/Trabalhos/Preservacao Digital-Vitor Lopes.pdf

Luna, S. V. (1997). Planejamento de pesquisa: uma introdução. São Paulo: EDUC.

Márdero Arellano, M. Á. (2004). Preservação de documentos digitais. Ciência da informação, 33(2), 15-27.

http://revista.ibict.br/ciinf/article/view/1043/1113

Márdero Arellano, M. Á. (2008). Critérios para a preservação digital da informação científica (Tese de doutorado). Universidade Federal de Brasília, Brasília. Recuperado de http://repositorio.unb.br/handle/10482/1518

Paes, M. L. (2004). Arquivo: teoria e prática. Rio de Janeiro: Editora FGV.

Rocha, C. L., e Silva, M. (2007). Padrões para garantir a preservação e o acesso aos documentos digitais. Acervo, 20(1), 113-124. Recuperado de http://revista.arquivonacional.gov.br/index.php/revistaacervo/article/view/76/76

Rondinelli, R. C. (2005). Gerenciamento arquivístico de documentos eletrônicos: uma abordagem teórica da diplomática arquivística contemporânea. Rio de Janeiro: Editora FGV.

Rousseau, J. Y., e Couture, C. (1998). Os fundamentos da disciplina arquivística. Lisboa: Publicações Dom Quixote.

Saramago, M. L. (2004). Metadados para preservação digital e aplicação do modelo OAIS. Em VIII Congresso Nacional de Bibliotecários, Arquivistas e Documentalistas. Anais eletrônicos... Estoril, Brasil. Recuperado de http://www.bad.pt/publicacoes/index.php/congressosbad/article/view/640/637 
Sayão, L. F. (2010). Repositórios digitais confiáveis para a preservação de periódicos eletrônicos científicos. Ponto de acesso, 4(3), 68-94. Recuperado de http://www.portalseer.ufba.br/index.php/revistaici/article/view/4709/3565

Silva, E. L., e Menezes, E. M. (2005). Metodologia da pesquisa e elaboração de dissertação. Florianópolis: Universidade Federal de Santa Catarina. Recuperado de https://projetos.inf.ufsc.br/arquivos/Metodologia_de_pesquisa_e_elaboracao de teses_e_ dissertacoes 4ed.pdf

Sousa, R. T. B. (2009). A classificação como função matricial do que-fazer arquivístico. Em V. B. Santos (Ed.), Arquivística: temas contemporâneos (pp. 79-172). Brasília: SENAC.

Thomaz, K. P. (2004). A preservação de documentos eletrônicos de caráter arquivístico: novos desafios, velhos problemas (Tese de doutorado). Universidade Federal de Minas Gerais, Belo Horizonte. Recuperado de http://www.bibliotecadigital.ufmg.br/dspace/bitstream/handle/1843/VALA68ZRKF/doutorado katia de padua thomaz.pdf

Thomaz, K. P. (2005). Documentos eletrônicos de caráter arquivístico: fatores condicionantes da preservação. Perspectivas em ciência da informação, 10(1), 34-53. Recuperado de http://portaldeperiodicos.eci.ufmg.br/index.php/pci/article/view/301

Thomaz, K. P. (2006). Gestão e preservação de documentos eletrônicos de arquivo: revisão de literatura - parte 2. Arquivística.net, 2(1), 114-131. Recuperado de http://www.brapci.ufpr.br/brapci/_repositorio/2009/11/pdf_c2f129fbdb 0006733.pdf

Thomaz, K. P. (2007). Repositórios digitais confiáveis e certificação. Arquivística.net, 3(1), 80-89. Recuperado de

http://basessibi.c3sl.ufpr.br/brapci/index.php/article/view/0000004775/b9771d939bc4cf2 8348a07ed8cd1a791

Webb, C. (2003). Guidelines for the preservation of digital heritage. National Library of Australia, UNESCO. Recuperado de

http://unesdoc.unesco.org/images/0013/001300/130071e.pdf 